\title{
Special Issue on Biomedical Engineering in the University of California System
}

We are honored and pleased to present the Special Issue on Biomedical Engineering in the University of California System. Through the years, we have been fortunate enough to learn first-hand about our colleagues' exciting areas of research at the Annual UC Systemwide Bioengineering Symposia and wanted to give you a glimpse of the cutting-edge research taking place across the UC campuses. We realize that one special issue cannot capture the breadth and depth of these research activities, but hope that this issue inspires you to take a closer look at the research of the biomedical engineering community in the UC system.

This special issue opens with a historical perspective from Professor Shu Chien, whose unwavering dedication and leadership were the driving forces that brought the bioengineering faculty of the UC campuses together as a multicampus research unit. In his contribution, Professor Chien discusses the timeline for the formation of the various UC bioengineering departments, the establishment of the Bioengineering Institute of California, and the historical progression of the Annual UC Systemwide Bioengineering Symposium, which is hosted by a different UC campus each year and is now in its second decade. Following this historical perspective, original contributions and reviews are clustered, in order of presentation, in the areas of (1) tissue engineering, (2) cellular and molecular engineering, (3) computational biology, (4) devices, and concluding with (5) imaging.

We have thoroughly enjoyed working with our colleagues in putting this special issue together. Reading about their new areas of research, as well as reviews on their specialties, have been very educational for us, and we sincerely hope you will enjoy this collection of articles that help demonstrate that the UC campuses are a rich environment for biomedical engineering research.

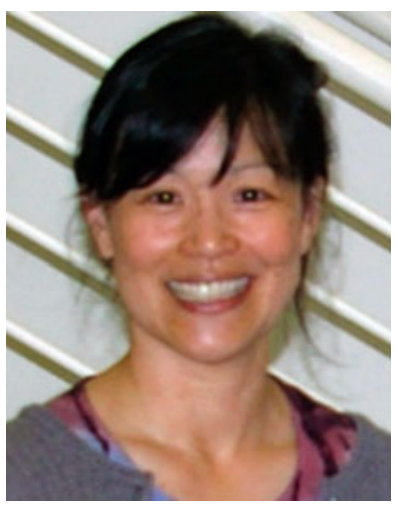

Angelique Louie

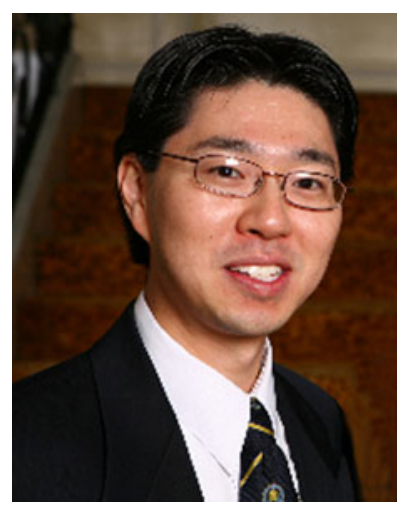

Daniel Kamei

\section{OPEN ACCESS}

This article is distributed under the terms of the Creative Commons Attribution Noncommercial License which permits any noncommercial use, distribution, and reproduction in any medium, provided the original author(s) and source are credited.

\author{
Angelique Louie \\ Guest Editor \\ Department of Biomedical Engineering \\ University of California \\ Electronic mail: aylouie@ucdavis.edu
}

Daniel KameI

Guest Editor

Department of Bioengineering

University of California

Electronic mail: kamei@seas.ucla.edu 